\title{
PCP dioxins found to pose health risks
}

Following wide debate on the hazards of TCDD, US scientists are now expressing concern about the possible health hazards of low-level exposure to other dioxins, particularly those in the widely-used wood preservative pentachlorophenol (PCP). David Dickson reports

SEVEN years ago, Dale Feucht, a dairy farmer in Canton, Ohio, decided to build a new barn for his herd of several hundred cattle. Two months after the animals had moved into their new home, they began to suffer various ailments, from general ill health to a rapid drop in the calf survival rate.

Veterinarians were at a loss to explain or treat a variety of apparently unrelated symptoms, affecting both existing stock and the animals bought to replace those that died. Within a few years, the herd had been decimated, and the last cattle died last summer.

Having eliminated changes in the water or feed supply as the source of the problem, suspicion focused on the one new factor in the environment, the barn. In particular high levels of pentachlorophenol (PCP), used to treat the wood as a preservative, was found in blood samples from the dead animals - assumed to result from the cattle chewing or rubbing the wood.

$\mathrm{Mr}$ Feucht is now suing the barn manufacturers, Morton Company. The case, to be heard in Ohio within the next few weeks, is being watched by many large chemical companies.

For PCP is currently one of the most widespread chemicals in domestic use, particularly in demand for its highly effective anti-fungal and anti-bacterial properties. Over 50 million pounds are produced annually by over 250 companies, and world-wide production is more than 100 million pounds.

Recent events, however, have started to fuel public controversy over the long-term, low level effects of dioxins that have so far been largely overshadowed by the more obvious effects of the most toxic dioxin, tetrachlorobenzo-p-dioxin (TCDD), both a contaminant of the herbicide $2,4,5$-T, and the chemical released in the Séveso accident in 1976.

The toxic properties of PCP itself have been known for some time. Ironically it was the development of oedema in chicks that first warned scientists of the possible dangers of dioxins. Little is known of the physical, chemical and toxicological properties of other dioxins, particular the hexa-, hepta-, and most prevalently in PCP, the octachlorodibenzo-p-dioxin.

So far, no firm action has been taken against PCPs, which remain on the shelves of hardware stores throughout the country merely with warnings about the need for careful use. Timber companies, for example, do not issue warnings with wood that has been treated with PCP.

Two years ago, the Environmental Protection Agency, following evidence of the teratogenicity and feto-toxicity of PCP during animal laboratory tests, announced that it was studying whether tougher regulations were needed. These are now expected to be published later in the year.

In the meantime, the lack of strict regulations meant that the Dow Chemical Company, having introduced a new preservative, Dowicide EC7, in which dioxin levels had been reduced two orders of magnitude by using more expensive production techniques, found the product uncompetitive against rival, nondecontaminated brands. Dowicide EC7 has now virtually disappeared from the market place.

But the political momentum previously lacking may now have arrived. Last year residents near the Lexington Blue Grass army depot in Kentucky started to claim that a high local incidence of leukaemia, as well as various other medical disorders, was the result of exposure to PCP used to preserve ammunition boxes at the depot.

Not only had workers in the depot been exposed to the chemical, but wood from the boxes had been sold off for as little a one dollar a car load. This was used primarily for firewood, but investigators subsequently found a range of other uses, including the construction of porches, barns, chicken coops and pigpens.

Following information collected by a local physician, a preliminary study carried out for the EPA by research workers from the University of Miami confirmed that there appeared to be an abnormally high incidence of leukaemia in the area.

Further data are now being collected by researchers from the National Institute of Occupational Safety and Health. They face a double detective task: first to discover whether the leukaemia incidence is substantiated by epidemiological data: secondly to determine whether, given the other substances at the base heavily used duirng the Vietnam War to store chemical warfare agents, the blame can be placed on the PCP.

But in the wake of the Agent Orange and Séveso incidents, suspicion has been focused on the wood preservative and the contaminants that it contains. And in addition to results of laboratory animal studies, this suspicion is also supported by recent research carried out at the National Institute of Environmental Health Sciences and North Carolina State University into the effects of PCP in cattle feed.

Research workers at the two institutions conducted a study under which five groups of heifer were compared over a 160-day period. One group was given a feed containing analytical PCP prepared in the laboratory, a second fed with technical PCP containing the dibenzodioxin and dibensofuran contaminants found in commercial preparations. Two groups were given a mixture of the two. The fifth group was used for control.

The results of the research, which are soon to be published, indicate a number of dose-related effects in the heifers exposed to the contaminated PCP, compared to the controls or those exposed to the analytical PCP. These included a decrease in body weight and feed efficiency, as well as progressive anaemia, and at the end of the test the researchers found a number of unexpected lesions in cattle using the contaminated feed, in particular in the mucosa of the urinary bladder through which the PCP would have been secreted.

"The results of our study show clearly that the toxicity of PCP in cattle is primarily attributable to its contamination with toxic impurities, either the dibenzodioxins or the dibenzofurans," says Dr Eugene McConnell, head of the Comparative Pathology Section of NIEHS and principal investigator of the study.

Which of the two is the culprit has not been demonstrated, but the North Carolina results are broadly compatible with evidence from low level exposure of monkeys to dioxins currently being carried out by Dr James Allen at the University of Wisconsin. Despite its lack of conclusiveness, such scientific evidence is likely to play an important role in forthcoming court cases.

William Brown, the attorney representing $\mathrm{Mr}$ Feucht, said last week that he was already dealing with two other PCP. related claims, one from a family that had built a house from PCP-treated timber supplied by a do-it-yourself construction company, the other from a farmer claiming disability after handling PCP-treated posts.

Mr Brown added that he had been contacted by others with similar complaints. A number of other court cases are pending in Michigan. "Everyone is watching this case very closely," says $\mathrm{Mr}$ Brown, pointing to the widespread use of PCP-treated timber, not only in homes and farm buildings, but also for railway sleepers and telegraph poles. "I really think it is the tip of the iceberg." 